\title{
ANÁLISE DA PRODUÇÃO CIENTÍFICA SOBRE ENERGIA MAREMOTRIZ
}

\author{
Daiane Costa Guimarães \\ Universidade Federal de Sergipe (UFS) - Av. Marechal Rondon, s/n Jardim Rosa Elze - CEP \\ 49100-000 - São Cristóvão/SE \\ dayaned10@hotmail.com \\ Adonis Reis de Medeiros Filho \\ Universidade Federal de Sergipe (UFS) - Av. Marechal Rondon, s/n Jardim Rosa Elze - CEP \\ 49100-000 - São Cristóvão/SE \\ adonisrmf@gmail.com \\ Jonas Pedro Fabris \\ Universidade Federal de Sergipe (UFS) - Av. Marechal Rondon, s/n Jardim Rosa Elze - CEP \\ 49100-000 - São Cristóvão/SE \\ jpfabris@hotmail.com \\ Suzana Leitão Russo \\ Universidade Federal de Sergipe (UFS) - Av. Marechal Rondon, s/n Jardim Rosa Elze - CEP \\ 49100-000 - São Cristóvão/SE \\ suzana.ufs@hotmail.com
}

\section{RESUMO}

O crescimento do consumo da energia elétrica mundial e a matriz energética estão apresentando grande dependência dos recursos não renováveis. Apontam para riscos eminentes para conservação do desempenho das atividades básicas, do cotidiano da população, visto que alguns estudos, já mencionam o tempo finito de cada fonte não renovável de energia, com base no período de crise do petróleo na década de 70 . Surge então a necessidade de exploração do uso de fontes renováveis de energia elétrica. Portanto este estudo objetiva investigar a produção científica sobre energia produzida pelas marés. Para atingir os objetivos foi feita uma busca na Web of Science, utilizando os termos "Tidal Power OR Tidal Energy" nos campos de título e resumo. Os dados coletados foram organizados no Microsoft Excel, onde gráficos foram produzidos. Os resultados mostram que os estudos são realizados desde 1949, mas o crescimento exponencial das pesquisas ocorreu somente a partir do século 21, liderada pelos Estados Unidos da América com maior participação nas publicações. A temática tem sua importância explicitada nas revistas onde as pesquisas foram publicadas, onde quase a totalidade apresenta fator de impacto bastante elevado.

\section{Palavra - Chave: Energia Maremotriz, Produção Científica, Web of Science.}

\begin{abstract}
The growth in world electricity consumption and the energy matrix are showing a great dependence on non-renewable resources. They point to imminent risks for conserving the performance of basic activities, of the daily life of the population, as some studies already mention the finite time of each non-renewable energy source, based on the period of oil crisis in the 70's. the need to explore the use of renewable sources of electricity. Therefore this study aims to investigate the scientific production on energy produced by the tides. To achieve the objectives, a Web of Science search was performed using the terms "Tidal Power OR Tidal Energy" in the title and abstract fields. The data collected was organized in
\end{abstract}


Microsoft Excel, where charts were produced. The results show that studies have been conducted since 1949, but the exponential growth of research occurred only from the $21 \mathrm{st}$ century, led by the United States of America with greater participation in publications. The theme has its importance explicit in the journals where the research was published, where almost all have a very high impact factor

\section{Keywords: Tidal Energy, Scientific Production, Web of Science.}

\section{INTRODUÇÃO}

A crescente demanda por energia associada ao curto horizonte dos combustíveis fósseis, bem como os aspectos ambientais relacionados ao consumo destes, tem desafiado o setor energético mundial a buscar novas fontes energéticas, sendo algumas destas bastante promissoras e relativamente recentes (NETO, et al., 2011).

A geração de energia elétrica proporciona diversos aspectos positivos e negativos para a região beneficiada. Positivo por proporcionar o bem-estar social e crescimento econômico, além de ser considerado o vetor de desenvolvimento responsável pelo crescimento da produção, indispensável para qualquer estratégia de desenvolvimento socioeconômico de uma região (ANELL 2012). Negativo, pois os impactos ambientais e sociais, gerados para a obtenção de energia elétrica vêm sendo discutidos mundialmente, mediante a conscientização da gravidade da questão (INATOMI, 2014).

Sendo assim, a maior parte de energia provém de fontes não renováveis, como os combustíveis fósseis, cuja queima resulta na emissão de gases do efeito estufa, causadores do aquecimento global. Para ter a redução dessa dependência de combustíveis fósseis, o mundo precisa de uma revolução de energia limpa, que exigirá um investimento sem precedentes em Ciência, Tecnologia e Inovação na área das energias renováveis.

Estudos Científicos buscam contextualizar, as fontes energéticas, formadas por matérias capazes de gerar energia através da sua transformação, são divididas em dois grupos: renováveis e não renováveis. As fontes não renováveis possuem reservas limitadas e levam muito tempo para se recuperar ou se renovar. Já as fontes renováveis, possuem uma capacidade maior e mais rápida de regeneração, além de serem inesgotáveis (CARVALHO, 2003).

No rol das energias renováveis destacam-se as energias das marés que constituem uma fonte energética bastante promissora e, portanto e tem sido apontada como uma das mais importantes fontes de energia renovável (ASTARIZ \& IGLESIAS, 2015), estando incluída neste grupo a energia maremotriz a qual pode ser gerada pelas marés tanto pelas oscilações de suas correntes, quanto pela diferença de altura entre maré alta e maré baixa. 
Portanto, a fim de ampliar o conhecimento referente à produção científica relacionada à energia das marés, este estudo teve como objetivo investigar a produção científica sobre energia produzida pelas marés analisando as características das publicações sobre as palavras chaves Tidal Power OR Tidal Energy" nos campos de título e resumo.

O artigo está estruturado da seguinte maneira: inicialmente, será apresentada a revisão teórica, em seguida a metodologia empregada. Por último apresenta-se a análise e discussão dos resultados encontrados concluindo com as considerações finais.

\section{REVISÃO TEÓRICA}

\subsection{Energia Renovável}

Os grandes desafios associados ao setor energético mundial tais como a crescente demanda de energia e limitações relacionadas ao uso de recursos fósseis, têm proporcionado um aumento significativo no desenvolvimento e utilização de fontes renováveis de energia (LEITE et al. 2010).

Para Ferreira et al (2016), todas as vezes que os problemas ambientais vêm à tona procuram-se meios para se reverter ou ao menos amenizar seus impactos. E as energias renováveis são sempre contempladas nas principais discussões mundiais quando a temática é abordada. Embora a sociedade conviva com inúmeras fontes de informações, a compreensão sobre energia renovável e quais fontes são consideradas renováveis é primordial para o entendimento das argumentações apresentadas.

Sendo assim, de acordo com a International Energy Agency - IEA (2015) considerase, portanto, fonte de energia renovável as fontes cuja velocidade de renovação é superior à velocidade de consumo, e dentro desta definição são fontes renováveis: a Geotérmica, Eólica, Energia Solar, Hídrica, Bioenergia e a Energia do Mar.

E de fato não há como deixar de se considerar nas pesquisas sobre energia renovável sem a abordagem do desenvolvimento sustentável. O aumento da temperatura média da superfície da terra resultante do crescente aumento do dióxido de carbono $\left(\mathrm{CO}_{2}\right)$ e de outros gases causadores do efeito estufa colocam em xeque as atuais fontes energéticas de origem fóssil (OMER, 2008), fazendo com que especialistas e governos mencionem a necessidade da inclusão e descoberta de fontes renováveis de energia como pré-requisitos para o desenvolvimento de uma sociedade mais sustentável (FERREIRA et al. 2016).

Além do aumento da temperatura se somam as discussões: a degradação do ecossistema, a destruição da camada de ozônio e as chuvas ácidas. 


\subsection{Energia das Marés (Maremotriz)}

A energia obtida através dos desníveis das marés passou a ser utilizada a partir do século XII, principalmente por camponeses na Inglaterra e França para moer cereais e demais semente, este procedimento era feito com a capitação do desnível das marés e sua velocidade (energia maremotriz e cinética respectivamente), transformando toda a energia captada em energia cinética para o moinho, ilustrada na Figura 1 (SILVA et al. 2018).

Com o passar dos anos, os seres humanos seguiram pesquisando profundamente sobre os diversos tipos de obtenção de energia, assim, descobriram que a energia retirada da diferença de altura entre as marés baixas e altas acontece devido à atração gravitacional e o movimento de rotação da terra, esta por sua vez demora aproximadamente 12 horas para alterar entre essas duas marés.

Figura 1 - Moinho de Água

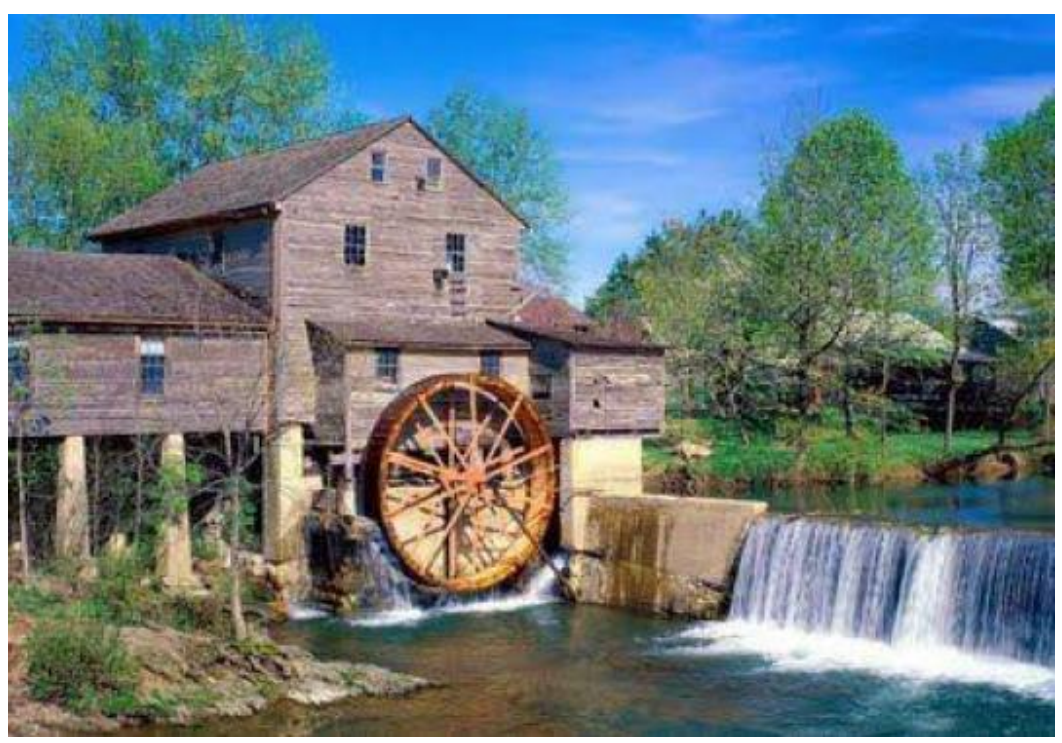

Fonte: (SILVA, et al. 2018, p. 121)

Além disso, a maremotriz é a forma de energia que utiliza o enorme poder das marés. O potencial mundial das energias das marés foi estimado em 3.000 GWA pelo relatório da World Offshore Renewable de 2004, no entanto menos de 3\% dessa energia localizam-se em áreas adequadas para geração de energia.

Ademais, a energia das marés tem sido aproveitada usando grandes barragens em áreas de altas amplitudes de marés. Muitos países, como Reino Unido, Rússia, China, França... Possuem grandes amplitudes de marés e locais viáveis para instalações de captação de energia das marés (OLIVEIRA, 2011). 
Uma usina maremotriz funciona de acordo com a variação do nível das marés. Conforme a maré sobe, parte da água fica represada. Quando a maré baixa, a água represada atravessa uma turbina tipo bulbo, gerando energia elétrica. A figura abaixo ilustra o funcionamento de uma planta maremotriz.

Figura 2 - Ilustração do funcionamento de uma usina maremotriz
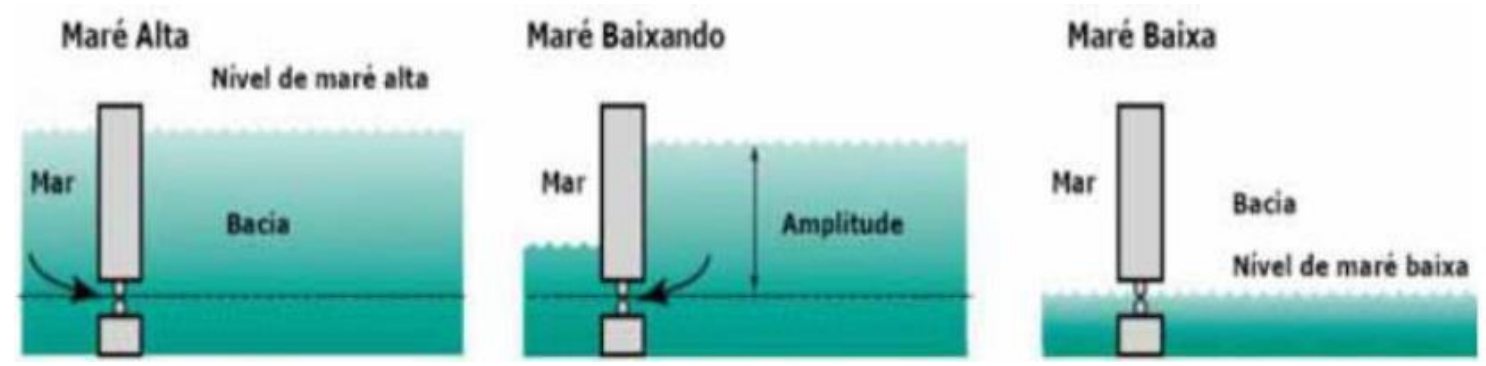

Fonte: (OLIVEIRA, 2011 p. 21)

Para Silva (2012), existem poucos lugares no mundo com capacidade de instalação de uma usina maremotriz. Tavares (2005) fala que o Brasil possui potencial para a instalação desse tipo de planta nas regiões do Norte e Nordeste, especialmente nos estados do Pará, Amapá e Maranhão, onde a diferença entre as marés baixa e alta varia de 8 a 11 metros.

\subsubsection{Vantagens e Desvantagens}

Como toda fonte de geração de energia, a maremotriz também apresenta vantagens e desvantagens. Em Energias Renováveis, temos algumas desses aspectos apresentados, conforme a Tabela 1.

Tabela 1 - Vantagens e desvantagens da energia maremotriz

\begin{tabular}{cc}
\hline \hline Vantagens & Desvantagens \\
\hline Não é poluente & $\begin{array}{c}\text { O fornecimento da energia das ondas não é contínuo } \\
\text { Apresenta baixo rendimento, cerca de } 20 \% \\
\text { Eonte renovável } \\
\text { É fortemente dispendiosa }\end{array}$ \\
$\begin{array}{c}\text { Não requer material } \\
\text { muito sofisticado }\end{array}$ & $\begin{array}{c}\text { Destrói habitats naturais de diversas espécies de animais } \\
\text { Impossibilita a navegação }\end{array}$ \\
\hline \hline
\end{tabular}

Fonte: Elaborado pelos autores, baseado nas informações SESMIL, p. 34. 2013. 


\section{METODOLOGIA}

Com o objetivo geral de estudar a produção científica, a trajetória metodológica adotada constituiu na realização de pesquisa de caráter exploratório, com abordagem quantitativa (OLIVEIRA, 2004). Exploratório porque pretende não apenas configurar e diagnosticar o estágio atual sobre a relevância sobre energia das marés, mas também avaliar de que forma as contribuições científicas estão interferindo e contribuindo para este setor.

Quantitativo por abordar forma matemática e estatística da produção científica, gerando novas informações que podem contribuir para a compreensão de problemas relacionados à produtividade científica.

Os artigos analisados foram extraídos os dados na Web of Science é uma base de dados de citações científicas com base em assinaturas on-line originalmente produzido pelo Institute for Scientific Information, posteriormente mantido pela Clarivate Analytics, que fornece uma pesquisa abrangente de citações.

Portanto, foram utilizadas as palavras chaves "Tidal Power OR Tidal Energy" nos campos de título e resumo, encontrando assim, publicações do ano de 1949 a 2017, tendo um quantitativo de 9084 publicações. Os dados coletados foram organizados no Microsoft Excel, onde gráficos foram produzidos.

\section{ANÁLISE DOS DADOS}

A intensão da seleção e configuração destes parâmetros foi identificar, a quantidade de publicações existentes sobre energias das marés, o progresso do tema em publicações ao longo dos anos, principais autores em números de publicações, principais países em números de publicações, entre outros.

Desta foram encontrados 9084 documentos publicados neste assunto desde o ano de 1949, tendo um progresso ascendente e com maior representativa após o ano de 1991, como pode ser visto na figura 2.

Observa-se também, quando comparado o ano de 2017 em relação a 2016, houve uma queda de $18 \%$ no número de publicações. Em contrapartida analisando essa comparação no decorrer dos 60 anos, houve um crescimento significativo de $315 \%$ do número de publicações sobre essa fonte renovável tão importante, no período de 1949/2017. 


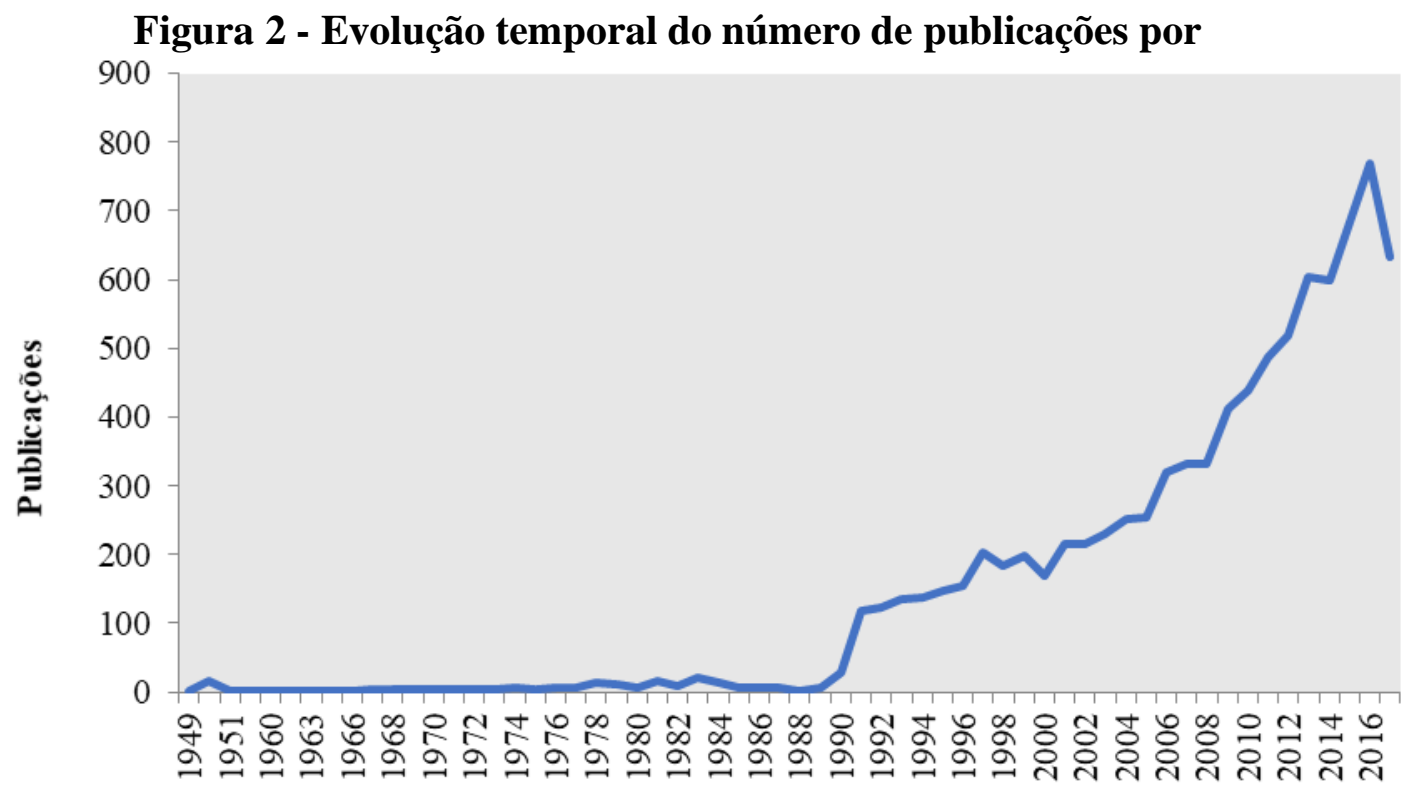

ano

\section{Anos}

Fonte: Elaborado pelos autores, baseado nos dados Web of Science

Em relação aos autores, abaixo segue os dez principais autores, os que mais publicaram sobre energias das marés.

Os 10 autores com maior número de publicações são responsáveis por 331 documentos (3,64\% do total das publicações), sendo que o autor mais prolífero no período foi Davies AM com 53 documentos, seguido do Van Haren H. com 36.

Figura 3 - Principais autores com maior número de publicações

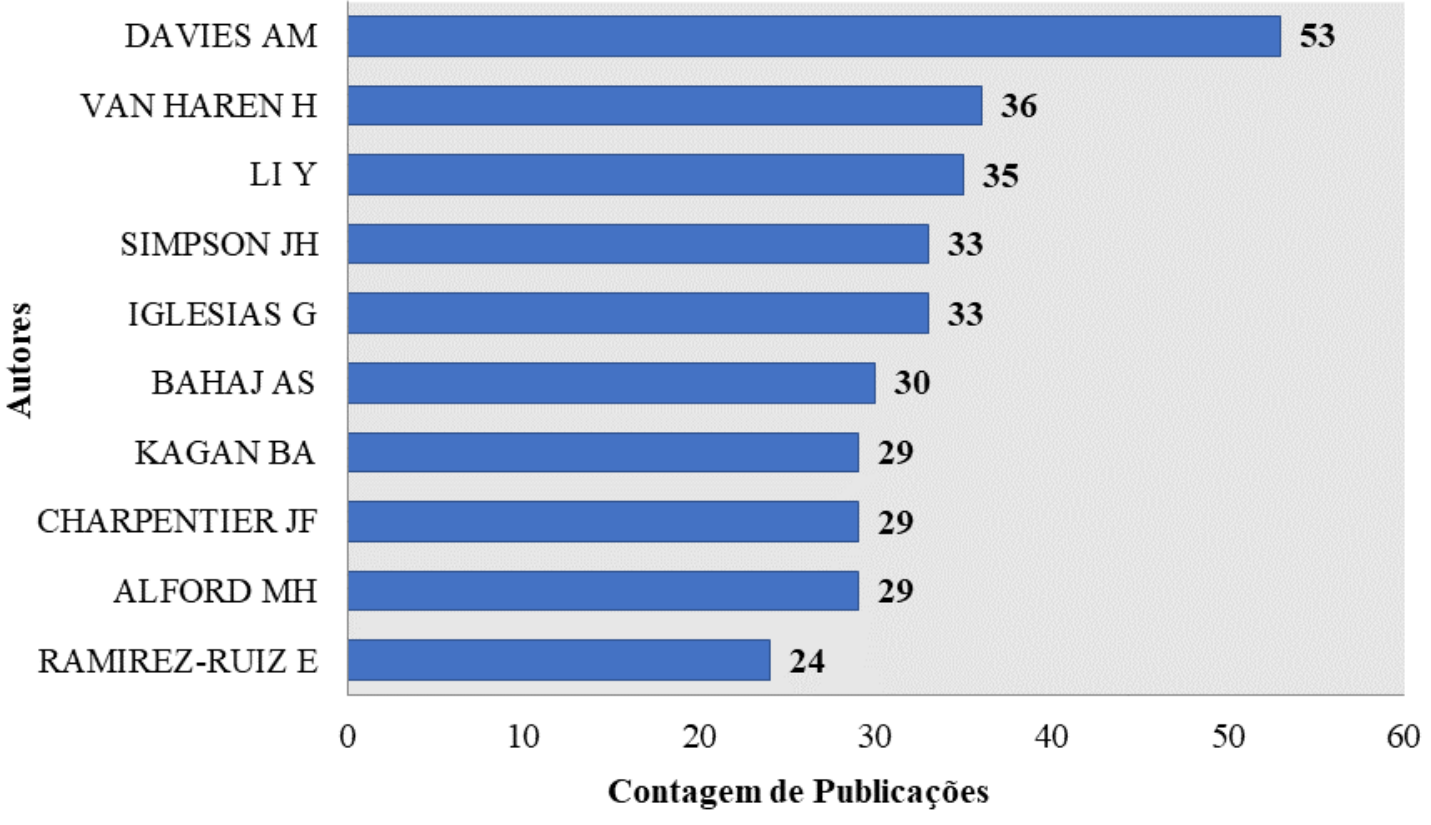

Fonte: Elaborado pelos autores, baseado nos dados Web of Science 
Também foi possível identificar os 10 principais países do mundo, com maior índice de publicação sobre o tema. A figura 4 apresenta em ordem do maior para o menor, os 10 países com maior volume de publicação.

Analisando a figura 4, pode-se observar que a posição número 1 pertence aos Estados Unidos com 3089 publicações uma representativa de (35\%), em $2^{\circ}$ lugar a Inglaterra com 1256, já em $3^{\circ}$ lugar China com 790 e assim sucessivamente. O Brasil não aparece no ranking dos 10 principais países que publicam mais sobre energia das marés ou maremotriz.

Além disso, nota-se também, que não houve nenhuma publicação sobre o tema estudado para o Brasil. Conforme diz Oliveira (2016), que o país não possui uma legislação para fontes renováveis de energia do mar, ele afirma ainda que, apesar dos avanços na legislação ambiental brasileira nas últimas décadas, "não são sequer citadas às tecnologias para geração de energias de fontes oceânicas”.

Portanto, no Brasil, pesquisas em energia oceânicas ainda são tímidas. Existe uma deficiência sobre a implementação de uma política estratégica de desenvolvimento voltada para esse tipo de fonte renovável, que direcione os recursos de $\mathrm{P} \& \mathrm{D}$ e a capacitação de recursos humanos.

Figura 4 - Ranking mundial dos países com maior número de publicações

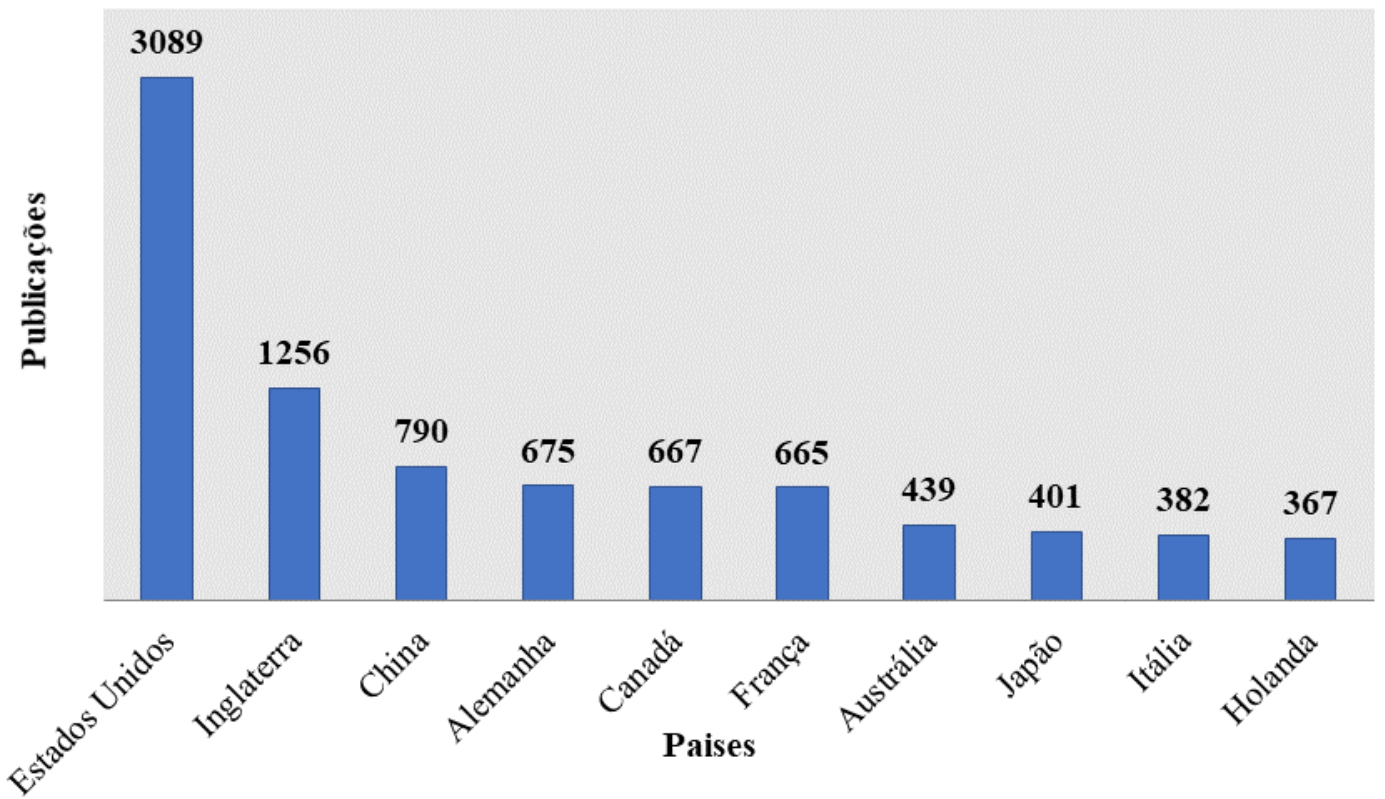

Fonte: Elaborado pelos autores, baseado nos dados Web of Science

$\mathrm{Na}$ análise, buscou-se também verificar as principais organizações que contemplam este tema em suas publicações. Observa-se a Universidade "University of Washington" com 215 publicações, seguida da “Caltech” com 180. 
A Universidade de Washington (em inglês, University of Washington / UW) é uma universidade pública de pesquisa em Seattle, Washington, Estados Unidos. Fundada em 1861, a UW é a maior universidade do noroeste americano e uma das mais antigas da costa oeste. É uma das universidades mais prestigiadas do mundo no que se refere ao ensino e à pesquisa.

A Universidade juntamente com o Estado de Washington tem uma preocupação e cuidado com energias renováveis como o todo. Portanto, um artigo da Universidade de Washington publicado em 20 de maio na revista Energy Research \& Social Science analisou as percepções dos moradores de Washington e o apoio à energia das marés, uma indústria nascente nos EUA que está 20 anos atrás da energia eólica terrestre.

O estudo constatou que as pessoas que acreditam que a mudança climática é um problema e veem benefícios econômicos, ambientais e / ou sociais ao uso de energia das marés são mais propensos a apoiar tais projetos. Além disso, conectar projetos piloto à rede elétrica é um fator importante para obter apoio público (UW, 2017).

Além disso, o segundo lugar é do "Caltech"- Instituto de Tecnologia da Califórnia é uma das primeiras universidades do mundo em pesquisa, a Caltech mantém uma forte ênfase e tradição nas ciências naturais e engenharia.

Figura 5 - Organizações com maiores números de publicações

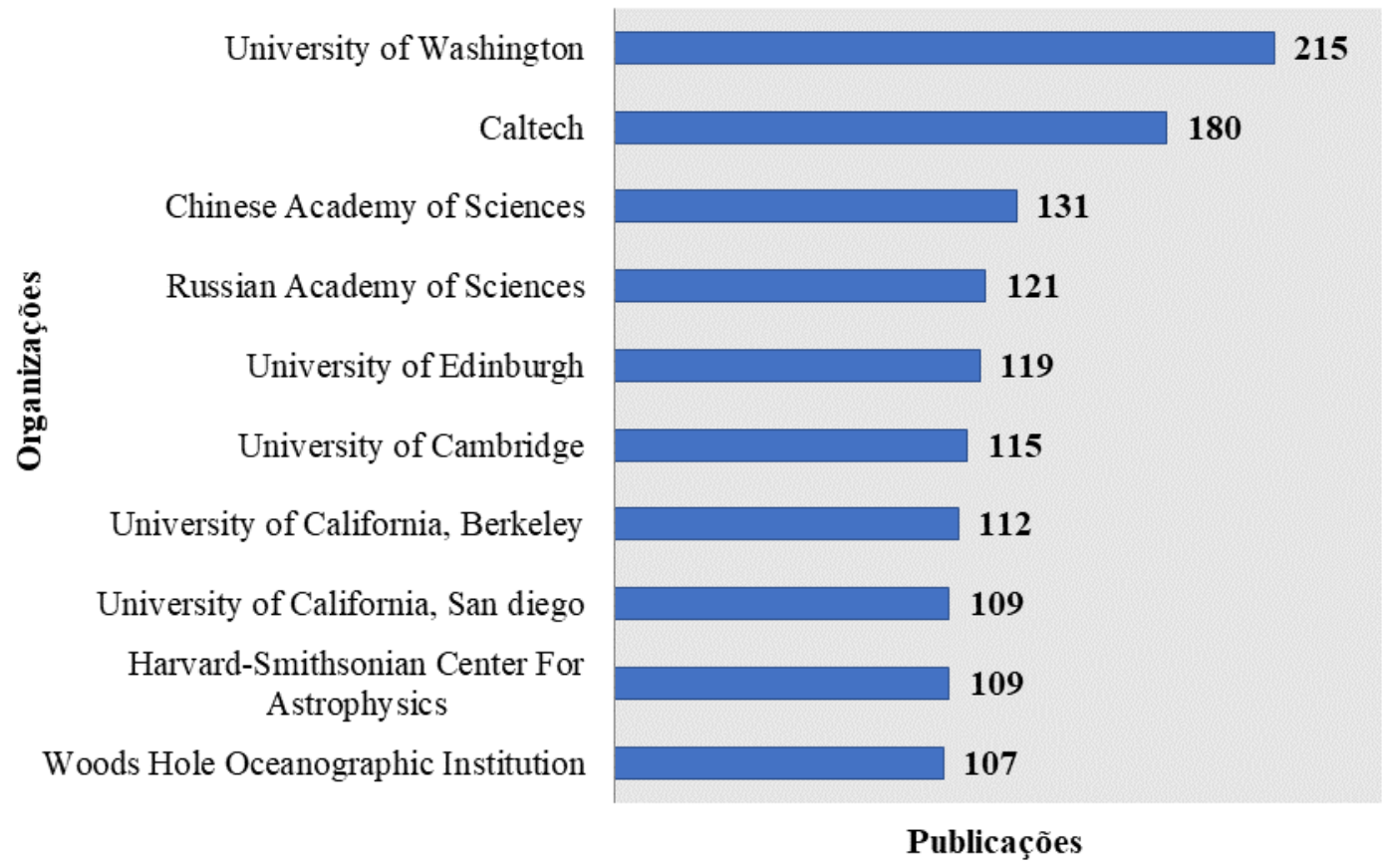

Fonte: Elaborado pelos autores, baseado nos dados Web of Science 
É importante mencionar as agências financiadoras sobre o tema estudado, pode - se observar na figura 6, as dez principais agências, sendo que a Nacional Science Foudation ganhou a primeira posição com o quantitativo de 510 publicações, representa $40 \%$.

A Fundação Nacional da Ciência (NSF, National Science Foundation) é uma agência governamental dos Estados Unidos independente que promove a pesquisa e educação fundamental em todos os campos da ciência e engenharia (NSF, 2019).

Em segundo lugar o principal financiador foi a NASA com 210 (17\%) publicações.

\section{Figura 6 - Principais agências}

\section{financiadoras}

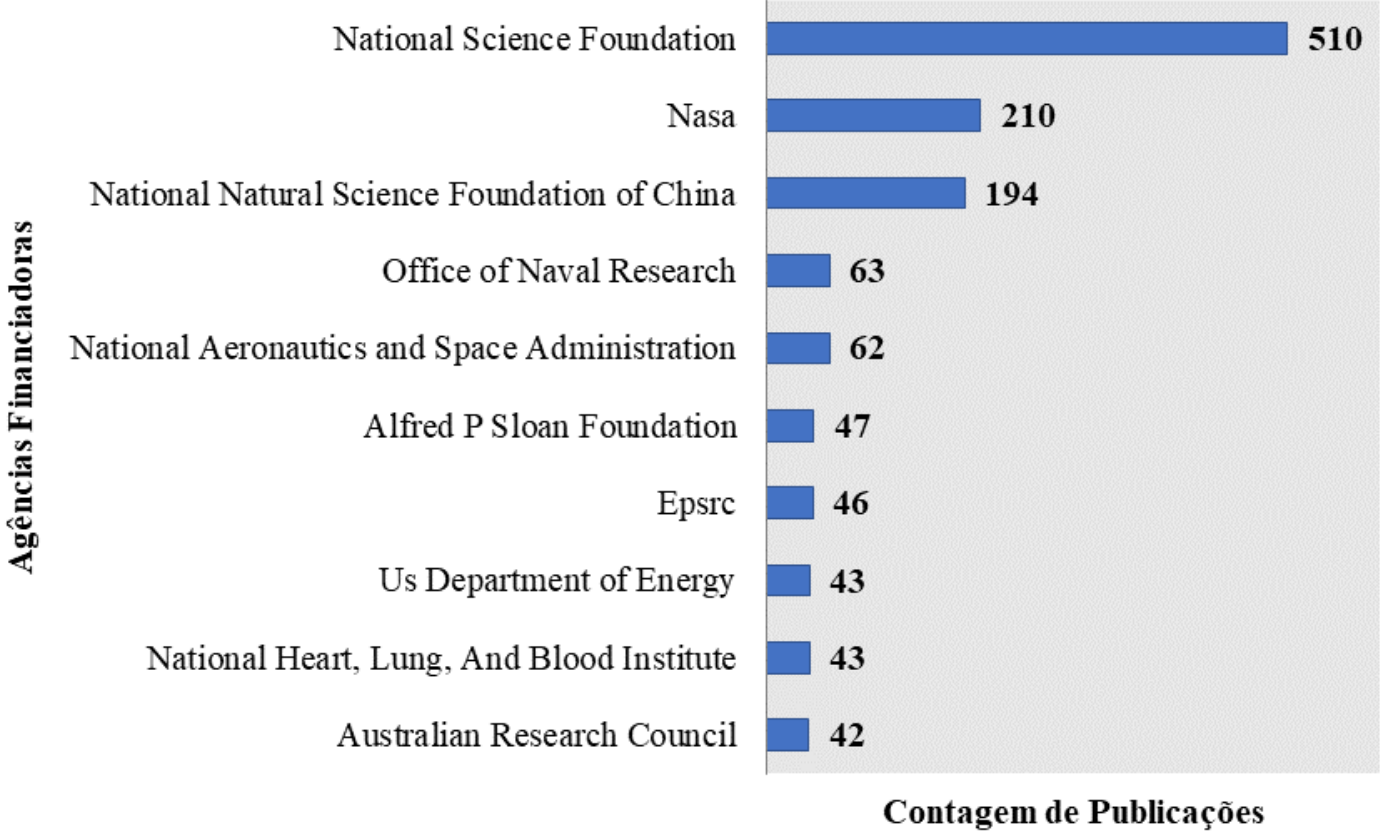

Fonte: Elaborado pelos autores, baseado nos dados Web of Science

$\mathrm{Na}$ figura 7 mostra as principais fontes de publicações sobre energia das marés, com 18,8\% tem-se o Astrophysical Journal com 5.533 números médios de citações de itens publicados recentemente no periódico (JCR), que serve para comparar diretamente periódicos referentes a uma mesma área do conhecimento e é um dos principais indicadores Bibliométrico mais amplamente utilizado.

Além disso, nota-se 2.863 prestígios científico do periódico (SJR), serve para comparar diretamente periódicos referentes a diferentes áreas do conhecimento e elimina manipulação: para aumentar seu valor é preciso publicar em periódicos com maior prestígio, conforme mostra a tabela 2(FERNANDES et al., 2016). 
Figura 7 - Principais fontes de publicações

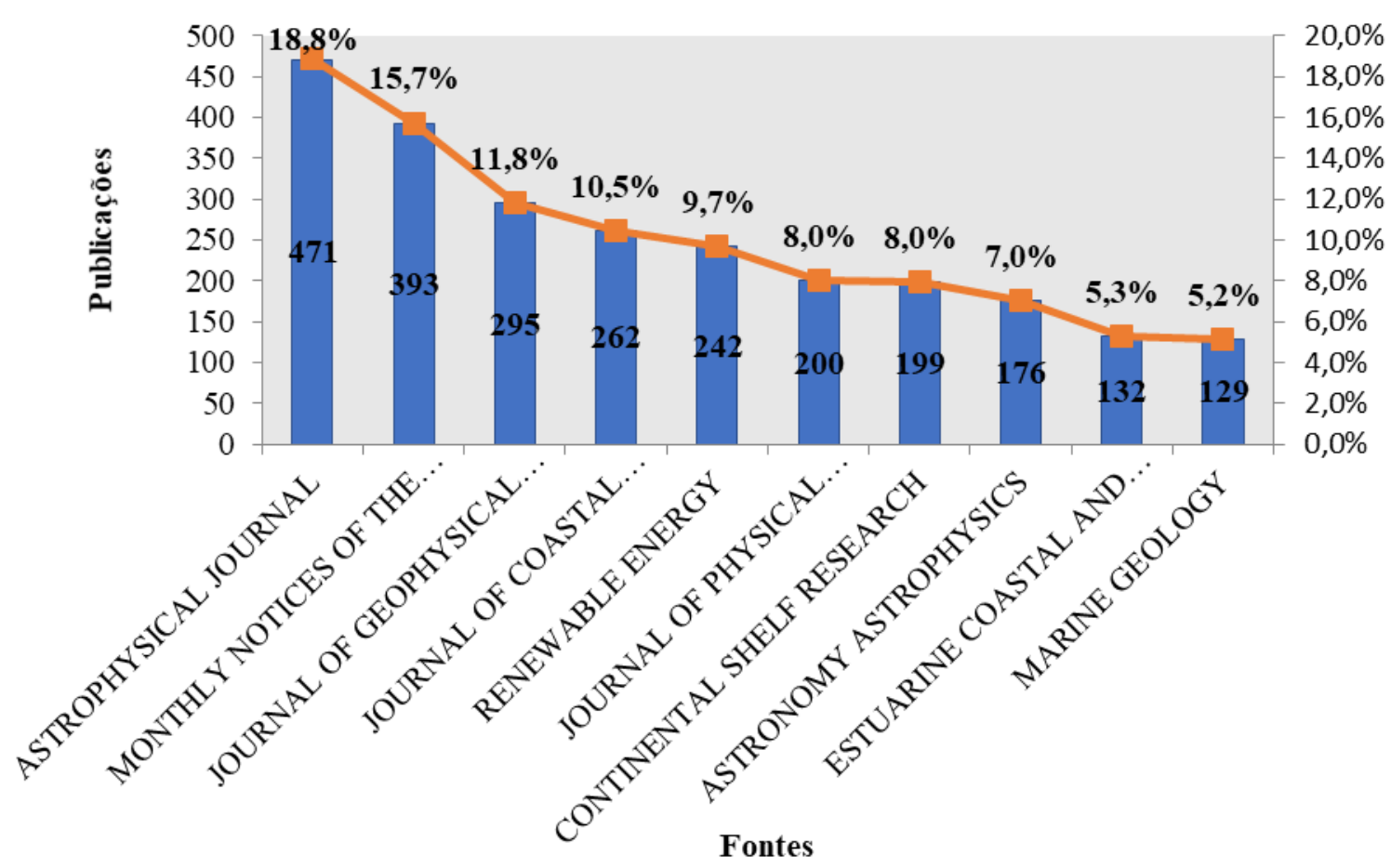

Fonte: Elaborado pelos autores, baseado nos dados Web of Science

Tabela 2 - Principais fontes

\begin{tabular}{cccc}
\hline \hline Títulos das fontes & JCR & SJR & QUALIS \\
\hline Astrophysical Journal & 5.533 & 2.863 & A1 \\
Monthly Notices of the Royal Astronomical S. & 4.961 & 2.338 & A1 \\
Journal of Geophysical Research Oceans & 2.939 & - & - \\
Journal of Coastal Research & 0.915 & 0.564 & A2 \\
Renewable Energy & 4.357 & 1.697 & A1 \\
Journal of Physical Oceanography & 3.130 & 2.760 & A2 \\
Continental Shelf Research & 2.064 & 1.051 & A2 \\
Astronomy Astrophysics & 5.014 & 2.246 & A1 \\
Estuarine Coastal And Shelf Science & 2.176 & 0.997 & A1 \\
Marine Geology & 3.572 & 1.537 & A1 \\
\hline \hline
\end{tabular}

Fonte: Elaborado pelos autores, baseado nos dados Web of Science 


\section{CONCLUSÕES}

As prioridades do setor energético mundial colocam as fontes alternativas em posição de destaque, tendo em vista que a maior participação destas na matriz energética mundial será uma tendência inevitável nos próximos anos, portanto, os estudos sobre a produção científica da energia das marés (maremotriz) tornam-se de bastante interesse sob o ponto de vista estratégico, econômico e ambiental.

Portanto, baseado na análise dos resultados foi possível concluir que o tema abordado tem uma evolução e volume de publicação nos últimos anos. Que existe interesse dos pesquisadores em desenvolver trabalhos relacionados ao uso de fontes renováveis de energia elétrica.

Além disso, as análises mostram que os estudos são realizados desde 1949, mas o crescimento exponencial das pesquisas ocorreu somente predomina a partir do século 21 , liderada pelos Estados Unidos com maior participação nas publicações (35\%) seguido da Inglaterra.

Percebe-se que não houve nenhuma publicação no Brasil sobre energias das marés, concluindo assim, que o país precisa de mais incentivos para com esse tema que é tão relevante e importante para sociedade e o meio ambiente.

Segundo as palavras do Oliveira (2016), o Brasil existe um oceano de possibilidades e potencial que não deve ser ignorado, devendo o Brasil explorar a geração oceânica, traçar um robusto planejamento, iniciando com uma atualização dos dados sobre a potencialidade oceânica brasileira, passando pelo fomento ao desenvolvimento técnico e científico com parcerias internacionais e proposição de políticas públicas voltadas para o mercado de energias oceânicas.

Ainda, notou-se a os dez principais autores com maior número de publicações que são responsáveis por 331 documentos (3,64\% do total das publicações), sendo que o autor mais prolífero no período foi Davies AM com 53 documentos, seguido do Van Haren $\mathrm{H}$. com 36. Também foram analisadas as organizações com maiores publicações, sendo em primeiro lugar a Universidade "University of Washington" com 215 publicações, seguida da “Caltech" com 180. 
É de suma importância analisar as agências financiadoras sobre o tema estudado, onde analisou as dez principais agências, sendo que a Nacional Science Foudation ganhou a primeira posição com o quantitativo de 510 publicações, representando $40 \%$.

Por conseguinte, entende-se que a análise abordada permite que se identifiquem publicações sobre diferentes assuntos, que podem contribuir para ampliar as pesquisas como essa relacionada à fonte renovável de energia elétrica - energias maremotrizes ou das marés, permitindo que o Brasil melhore sua produção científica, visto que no país ainda a há pouca produção sobre esse assunto.

De maneira que, a temática tem sua importância explicitada nas revistas onde as pesquisas foram publicadas, onde quase a totalidade apresenta fator de impacto bastante elevado.

Ademais, como possíveis estudos futuros, sugere-se a analisar a produção tecnológica, através de depósito de patente sobre a energia maremotriz.

Recomenda-se, ainda, aos interessados no tema de energia maremotriz verificar através de uma análise Estatística a metodologia Box e Jenkins (modelos de series temporais) que faz previsões futuras em curto prazo, com o intuito de observar o crescimento futuramente ou não sobre as tecnologias maremotrizes, acompanhando assim sua evolução.

\section{REFERÊNCIAS BIBLIOGRÁFICAS}

ANEEL. Atlas de energia elétrica do Brasil. Aneel. 2012.

ASTARIZ, S.; IGLESIAS, G. The economics of wave energy: A review. Renewable and Sustainable Energy Reviews, v. 45, p. 397-408, 2015.

CARVALHO, P. Geração Eólica. Fortaleza: Imprensa Universitária, 2003.

FERNANDES, V.; SALVIANO, L. R. Indicadores JCR, SNIP, SJR e Google Scholar. Disponível em: http://portal.utfpr.edu.br/pesquisa-e-pos-graduacao/indicadores/indicadoresexternos/indicadores-externos. Acesso no dia 25 de fevereiro de 2019.

FERREIRA, H. L.; PUGAS, M. A. R.; PATAH, L. A. Estudo Bibliométrico das publicações sobre tecnologia solar entre os períodos de 2000 e 2015 . Encontro Internacional sobre gestão empresarial e meio ambiente, 2016. 
IEA. Internacional Energy Agency. Key Word Energy Statistics. v. 1, p. 1-81, 2015.

INATOMI, T. A. H.; UDAETA, MORALES. M. E. Análise dos impactos ambientais na produção de energia dentro do planejamento integrado de recursos. Disponível em: http://www.espacosustentavel.com/pdf/I.

LEITE N., P. B; SAAVEDRA, O. R; CAMELO, N. J; RIBEIRO, L. A. S. (2010), Viabilidade de Pequenos Aproveitamentos para Geração de Energia Eletromaremotriz. In: XVIII Congresso Brasileiro de Automática, 2010, Bonito: UNESP, 2010. v. 1. p. 66286.

NETO, O. B. L.; SAAVEDRA, O. R.; CAMELO, N. J.; RIBEIRO, L. A. S.; FERREIRA, R. M. Exploração de energia maremotriz para geração de eletricidade: aspectos básicos e principais tendências. Ingeniare. Revista chilena de ingeniería, vol. 19 No 2, 2011, pp. 219232.

NSF - Fundação Nacional da Ciência. Disponível em: https://www.nsf.gov/. Acesso no dia 25 de fevereiro de 2019.

OLIVEIRA, R. M. Energias Oceânicas: arcabouço legal e entraves a serem superados para o desenvolvimento no Brasil. Dissertação (Mestrado) - Programa de pós-graduação em Energia e Ambiente / CCET, Universidade Federal do Maranhão. São Luís, 2016.

OLIVEIRA, S. L. Tratado de metodologia científica : projetos de pesquisas, TGI, TCC. Monografias, dissertações e teses. São Paulo : Pioneira Thomson, 2004.

OMER, A. M. Energy, environment and sustainable development. Renewable and Sustainable Energy Reviews, v. 12, p. 2265-2300, 2008.

SESMIL, E. L. F. Energia Maremotriz: Impactos Ambientais e Viabilidade Econômica No Brasil. Monografia apresentada à Universidade Federal de Lavras. Programa de PósGraduação Lato Sensu em Fontes Alternativas de Energia, 2013.

SILVA, A. E.; BARRETO, G. B.; JUNIOR, H. R. S.; GONÇALVES, J. H. N.; AMARANTE, M. S. Energia Maremotriz. Pesquisa e Ação V4 N1: maio de 2018. 
SILVA, R. G. A geraçaõ de energia maremotriz e suas oportunidades no Brasil. Revista Ciências do Ambiente, Campinas, v.8. n. 2. P. 82-87, 2012.

TAVARES, W. M. Produção de eletricidade a partir de energia maremotriz. Brasília: Consultoria Legislativa da Câmara dos Deputados, 2005.

UW

Universidade

Washington.

Disponível

em:

http://www.washington.edu/news/2017/05/31/support-for-tidal-energy-is-high-amongwashington-residents/ (2017). Acesso no dia 25 de fevereiro de 2019. 